\title{
Partograph utilization as a decision-making tool and associated factors among obstetric care providers in Ethiopia: a systematic review and meta-analysis
}

Asteray Assmie Ayenew ${ }^{1 *}$ and Biruk Ferede Zewdu²

\begin{abstract}
Background: Globally, a total of 13.6 million women have died due to maternal causes from 1990 to 2015. Majority of these deaths occurred in resource-limited countries. Among the causes of these deaths, obstructed and prolonged labor covers the highest percentage, which could be prevented by cost-effective and affordable health interventions like partograph use. Therefore, this systematic review and meta-analysis aimed to assess the level of partograph utilization among obstetric care providers and its associated factors in Ethiopia.

Method: For this review, we used the standard PRISMA checklist guideline. Different online databases were used for the review: PubMed/Medline, Google Scholar, EMBASE, Cochrane Library, HINARI, WHO Afro Library Databases, and African Online Journals. Based on the adapted PICO principles, different search terms were applied to achieve and access all the essential articles. Microsoft Excel was used for data entry and Stata version 11.0 (Stata Corporation, College Station, TX, USA) for data analysis.

Result: Nineteen studies were included in this systematic review and meta-analysis with a total of 6237 obstetric care providers. The overall pooled prevalence of partograph utilization was 59.95\% (95\% Cl 46.8-73.09, $P^{2}=99.4 \%$, $P<0.001$ ). Being in midwifery profession (adjusted odds ratio (AOR) 3.97; 95\% confidence interval (CI) 2.63-5.99, $\left.P^{2}=28.8 \%, P=0.198\right)$, presence of supervision ( $\mathrm{AOR}=3.21 ; 95 \% \mathrm{Cl} 2.22-4.66, P=0.0 \%, P=0.742$ ), Basic Emergency Obstetric and Newborn Care (BEmONC) training (AOR $\left.=2.90 ; 95 \% \mathrm{Cl} 2.19-3.84, P^{2}=36.9 \%, P=0.13\right)$, knowledge of partograph $\left(\mathrm{AOR}=2.5 ; 95 \% \mathrm{Cl} 1.6-3.8, P^{2}=64.58 \%, P=0.024\right)$, on-the-job refresher training on partograph (AOR $=$ $\left.5.7 ; 95 \% \mathrm{Cl} 2.5-12.9, P^{2}=87.8 \%, P<0.001\right)$, favorable attitude (AOR $\left.=2.12 ; 95 \% \mathrm{Cl} 1.48-3.04, P=0.0 \%, P=0.58\right)$, and working at health center $\left(\mathrm{AOR}=3.50 ; 95 \% \mathrm{Cl} 2.49-4.92, P^{2}=49.1 \%, P=0.08\right.$ ) were the determinant factors for partograph use among obstetric care providers in Ethiopia.

Conclusion: The overall pooled prevalence of partograph utilization among obstetric care providers was low. Therefore, supportive supervision, providing Basic Emergency Obstetric and Newborn Care training, on-the-job refresher training on partograph, and promoting midwifery profession are strongly recommended to increase the use of partograph.
\end{abstract}

Keywords: Partograph utilization, Obstetric care providers, Systematic review and meta-analysis, Ethiopia

\footnotetext{
* Correspondence: amanuelbiruk0077@gmail.com

'Department of Midwifery, College of Medicine and Health Sciences, Bahir Dar University, Bahir Dar, Ethiopia

Full list of author information is available at the end of the article
}

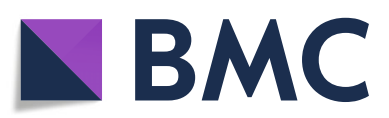

(- The Author(s). 2020 Open Access This article is licensed under a Creative Commons Attribution 4.0 International License, which permits use, sharing, adaptation, distribution and reproduction in any medium or format, as long as you give appropriate credit to the original author(s) and the source, provide a link to the Creative Commons licence, and indicate if changes were made. The images or other third party material in this article are included in the article's Creative Commons licence, unless indicated otherwise in a credit line to the material. If material is not included in the article's Creative Commons licence and your intended use is not permitted by statutory regulation or exceeds the permitted use, you will need to obtain permission directly from the copyright holder. To view a copy of this licence, visit http://creativecommons.org/licenses/by/4.0/. The Creative Commons Public Domain Dedication waiver (http://creativecommons.org/publicdomain/zero/1.0/) applies to the data made available in this article, unless otherwise stated in a credit line to the data. 


\section{Background}

Globally, a total of 13.6 million women have died due to maternal causes from 1990 to 2015. Of all the deaths, $99 \%$ were in developing countries with 546 per 100,000 live births, and sub-Saharan Africa only accounts $66 \%$ of deaths [1]. Additionally, there is a staggering evidence that peripartum fetal mortality and morbidity are directly related to the labor abnormalities like asphyxia, birth injuries, low Apgar scores (Appearance, Pulse, Grimace, Activity, and Respiration), and intrapartum or postpartum deaths. About $97 \%$ of all reported neonatal deaths occur in less developed countries. Of these, majority are a direct consequence of labor complications [2]. In Ethiopia, the tragedy of maternal and neonatal mortality is stagnant so far, in spite of the apparent commitment by stakeholders. In 2016, maternal mortality accounted for 412 per 100,000 live births and neonatal mortality was 29 per 1000 live births [3].

According to the World Health Organization (WHO), one of the key important requirements for averting these deaths is the provision of care by a skilled birth attendant before, during, and after childbirth [4]. Skilled birth attendant care needs to be available across all levels of the health system in order to reduce the delays for a referral to a higher care level if problems are expected to arise or do arise during labor. Thus, partograph is also used in conjunction with this intervention [5]. The partograph is a graphical record of the progress of labor and relevant details of the mother and the fetus. It has action and alert lines to stimulate commencement of additional interventions by a skilled birth attendant monitoring the progress of labor [6].

Partograph is an effective tool to monitor the progress of labor. When used effectively, it prevents obstructed labor, which is a leading cause of maternal and neonatal mortality, especially in developing countries [7-9]. Globally, it is estimated that obstructed labor occurs in 5\% of pregnancies and accounts for an estimated $8 \%$ of maternal deaths [10-12], whereas the prevalence of obstructed labor is $47 \%$ in Ethiopia and accounts for $9 \%$ of the total maternal death [3].

Friedman in 1954 studied the natural course of human labor and proposed a new way of plotting progress of labor in the first stage, against time, progress faster at the rate of $1.3 \mathrm{~cm} / \mathrm{h}$ in primigravida and $1.5 \mathrm{~cm} / \mathrm{h}$ in multigravida. Friedman devised a graph of labor depicting cervical dilatation and descent of fetal head in a graphical manner against time; this was known as "the Friedman's curve." The graph is a sigmoid curve divided into latent and active phase of labor [13]. The curve later became the basis of the modern partograph that is in clinical use today. The World Health Organization launched the partogram in 1987 as a safe motherhood initiative following a multi-center trial [14]. The first
WHO partograph or "composite partograph" covers a latent phase of labor of up to $8 \mathrm{~h}$ and an active phase beginning when the cervical dilatation reaches $3 \mathrm{~cm}$. The active phase is depicted with an alert line and an action line, drawn $4 \mathrm{~h}$ apart on the partograph. This partograph is based on the principle that during active labor, the rate of cervical dilation should not be slower than $1 \mathrm{~cm} /$ $\mathrm{h}$. Since a prolonged latent phase is relatively infrequent and not usually associated with poor perinatal outcome, the usefulness of recording the latent phase of labor in the partograph has been questioned. Moreover, differentiating the latent phase from false labor is often difficult [8]. To alleviate these disadvantages, a modified WHO partograph was introduced and incorporated removal of the latent phase and defined the beginning of the active phase at $4 \mathrm{~cm}$ cervical dilatation instead of $3 \mathrm{~cm}$ [15].

The World Health Organization recommends the universal utilization of the partograph during labor for routine monitoring of labor, and helps the health care provider in identifying slow progress in labor, and to make better decisions for the diagnosis and management of prolonged and obstructed labor [16, 17].

Moreover, partograph serves as an "early warning system" and assists in early decisions on transfer, intervention decisions in hospitals, and ongoing evaluation of the effect of interventions to prevent maternal deaths caused by prolonged labor. It has been promoted by the World Health Organization as the "gold" standard for assessing the progress of labor especially for low resource countries like Ethiopia [18, 19].

For pregnant women, obstructed labor remains an important cause of not only maternal death but also shortand long-term disability like obstetric fistula, uterine rupture, uterine prolaps, nerve damage, incontinence, puerperal sepsis, postpartum hemorrhage, and infertility from hysterectomy [20]. This can be prevented by accessing skilled delivery services such as plotting partograph during the progress of labor $[14,21]$. Therefore, this systematic review and meta-analysis aimed to estimate the pooled prevalence of partograph use among obstetric care providers and its determinant factors in Ethiopia.

\section{Methods}

This systematic review and meta-analysis was conducted to estimate the national use of partograph and its associated factors among obstetric care providers in Ethiopia. We used the Preferred Reporting Items for Systematic Reviews and Meta-Analyses (PRISMA) checklist guideline [22] (Additional file 1).

\section{Searching strategy}

First, the PROSPERO database and Database of Abstracts of Reviews of Effects (DARE) (http://www.library. UCSF.edu) were searched to check whether published or 
ongoing projects exist related to the topic. The literature search strategy, selection of studies, data extraction, and result reporting were done in accordance with the Preferred Reporting Items for Systematic Reviews and Meta-Analyses (PRISMA) guidelines [23]. We searched PubMed, Google Scholar, EMBASE, Cochrane Library, HINARI, WHO Afro Library Databases, and African Online Journal databases for all available studies using the following terms: "Partograph utilization," "knowledge on partograph," "labor," "on-the-job refresher training on partograph," "obstetric care providers," "midwives," "decision making tool," "attitude towards partograph," "labor monitoring," "first stage of labor," "health care providers," "health institutions," "childbirth," "factors," "determinants," "health institutions," "intrapartum monitoring," "components," "partograph," and "Ethiopia." The search string was developed using "AND" and "OR" Boolean operators. Searching terms were based on adapted PICO principles to search through the abovelisted databases to access all the relevant articles. For unpublished studies, the official websites of Ethiopian's university research repository online library (University of Gondar and Addis Ababa University) were used.

\section{Inclusion and exclusion criteria}

In this systematic review and meta-analysis, we included all observational studies (cross-sectional, case-control, and cohort studies) conducted in Ethiopia and only in English language. Additionally, studies that reported prevalence and/or risk factors, the outcome was partograph utilization as a decision-making tool, and participants of obstetric care providers and both published and unpublished studies at any time were included. However, studies available only as abstract with unclear outcomes, commentaries, editorials, reviews, and qualitative studies were excluded.

\section{Quality assessment}

After collecting the findings from all databases, the articles were exported to Microsoft Excel spreadsheet. Two authors (AAA and BFZ) independently extracted the data and reviewed the screened and eligible articles. Any disagreement was handled by the two reviewers (AAA and BFZ). Finally, a consensus was reached between the two authors through discussion. The methodological quality of each study (sampling strategy, response rate, and representativeness of the study), comparability, and outcome were checked using the NOS tool. NewcastleOttawa Quality Assessment Scale (NOS) for crosssectional and case-control studies was used to assess the methodological quality of a study and to determine the extent to which a study has addressed the possibility of bias in its design, conduct, and analysis [24]. All the included articles scored (NOS) 7, and more can be considered as "good" studies with low risk (Additional file 2).

\section{Outcome of measurement}

This review has two main outcomes. Partograph utilization among obstetric care providers to monitor the progress of labor and feto-maternal condition was the primary outcome of the study, whereas associated factors for partograph utilization among obstetric care providers were the second outcome variables. The odds ratio was calculated for the common risk factors of the reported studies. The most common associated factors included in this systematic review and meta-analysis were midwifery profession, presence of supervision, Basic Emergency Obstetric and Newborn Care (BEmONC) training, knowledge of partograph, on-thejob refresher training on partograph, favorable attitude towards partograph, and working at the health center.

\section{Data extraction}

Microsoft Excel (2016) and Stata version 11.0 (Stata Corporation, College Station, TX, USA) software were used for data entry and analysis, respectively. Two authors (AAA and BFZ) independently extracted all the important data using a standardized JBI data extraction format. The inter-rater agreement between authors for study inclusion, data extraction, and methodological quality will be assessed using Cohen's kappa coefficient (values $\leq 0$ as indicating no agreement and $0.01-0.20$ as none to slight, $0.21-0.40$ as fair, $0.41-0.60$ as moderate, $0.61-0.80$ as substantial, and $0.81-1.00$ as almost perfect agreement) [25]. Substantial agreement between reviewers, i.e., Cohen's kappa coefficient $>0.60$, was accepted. Any disagreement between reviewers was resolved through discussion, and then, consensus was reached. During data extraction, name of the author, sample size, publication year, study design, prevalence, response rate, population outcome, study site, and different contributing factors were included. Moreover, prevalence of partograph use with $95 \% \mathrm{CI}$ and associated factors were collected [26].

\section{Statistical analysis}

As the test statistic showed significant heterogeneity among studies $\left(I^{2}=99.4 \%, P<0.05\right)$, the random-effects model was used to estimate the DerSimonian and Laird pooled effect [27]. Cochran's $Q$ chi-square statistics and $I^{2}$ statistical test were conducted to assess the random variations between primary studies [28]. In this study, heterogeneity was interpreted as an $I^{2}$ value of $0 \%=$ no heterogeneity, $25 \%=$ low, $50 \%=$ moderate, and $75 \%=$ high [29]. In case of high heterogeneity, subgroup analysis and sensitivity analyses were run to identify possible 
moderators of this heterogeneity. Potential publication bias was assessed by visually inspecting funnel plots and objectively using Egger's test (i.e., $P<0.05$ ) [30]. To account for any publication bias, we used the trim-and-fill method, based on the assumption that the effect sizes of all the studies are normally distributed around the center of a funnel plot. The meta-analysis was performed using the Stata version 11.0 (Stata Corporation, College Station, TX, USA) software. Finally, for all analyses, $P<$ 0.05 was considered statistically significant.

\section{Results}

\section{Study selection and data extraction}

The search strategy identified 80 articles from PubMed, 60 articles from Google Scholar, 45 articles from Cochrane Library, 10 articles from African Journals Online, 7 articles from Ethiopian's university online library, and 5 articles by manual search. Of them, 134 were excluded due to duplication, and 35 through review of titles and abstracts. Additionally, 31 full-text articles were excluded for not reporting the outcome variable and other reasons. Finally, 19 were included to the prevalence and/or associated factor analysis on partograph use (Fig. 1).

\section{Study characteristics}

Different factors such as midwifery profession, presence of supervision, Basic Emergency Obstetric and Newborn Care (BEmONC) training, knowledge of partograph, onthe-job refresher training on partograph, favorable attitude towards partograph, and working at the health center were included in this study. Nineteen cross-sectional studies with a total of 6237 obstetric care providers were included in this review. All of the included articles were facility-based study setting. Regarding the study area, six of the studies were conducted at SNNPR (South Nation Nationalities and People Representative), four in Tigray, and three each in Amhara and Oromia, respectively (Table 1).

\section{Partograph use among obstetric care providers in Ethiopia}

The overall pooled prevalence of partograph is presented with a forest plot (Fig. 2). Therefore, the national

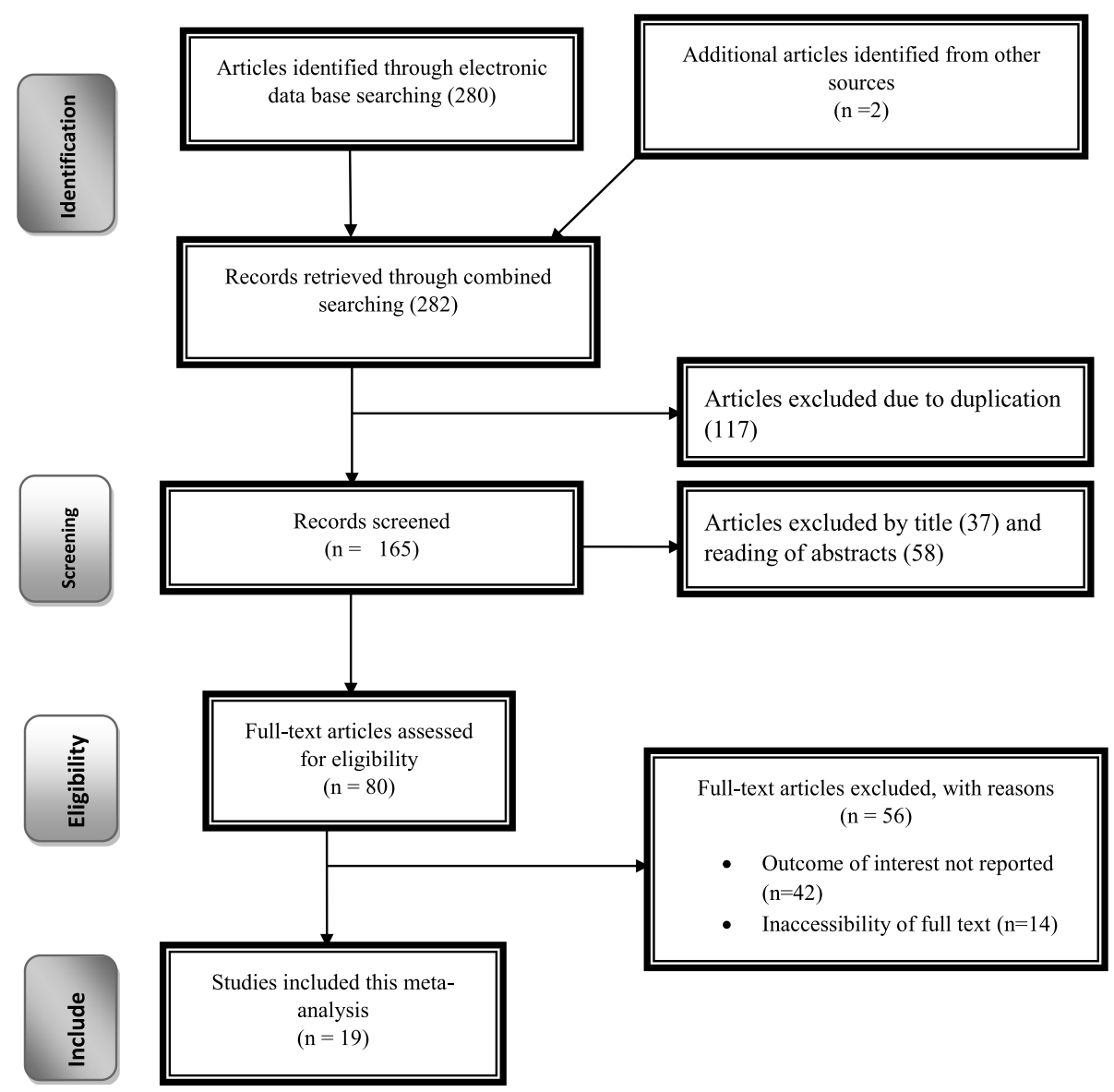

Fig. 1 Flow chart of study selection for systematic review and meta-analysis of partograph utilization as a decision-making tool among obstetric care providers in Ethiopia 
Table 1 Descriptive summary of nineteen included studies in the systematic review and meta-analysis

\begin{tabular}{llllll}
\hline Author (year of study) (reference number) & Sample size & Response rate (\%) & Study region & Prevalence (95\% Cl) & NOS quality of score \\
\hline Fantu et al. (2012) [31] & 381 & 88 & Amhara & $29(24-33)$ & 9 \\
Habtamu et al. (2017) [32] & 224 & 90.2 & Oromia & $89(85-93)$ & 9 \\
Wakeshe et al. (2015) [33] & 266 & 97.4 & Oromia & $84(80-88)$ & 9 \\
Negash et al. (2013) [34] & 403 & 94.5 & Amhara & $40(35-45)$ & 8 \\
Haymanot et al. (2015) [35] & 441 & 98 & Addis Ababa & $92.6(90-95)$ & 9 \\
Tesfay et al. (2017) [36] & 220 & 90 & Tigray & $73(67-79)$ & 9 \\
Desalegne et al. (2015) [37] & 273 & 100 & Amhara & $53(48-60)$ & 9 \\
Kidist et al. (2016) [38] & 300 & 93.3 & SNNP & $51(45-57)$ & 8 \\
Kidest et al. (2016) [39] & 442 & 99 & SNNP & $73(68-78)$ & 9 \\
Markos et al. (2014) [40] & 401 & 91 & SNNP & $70(66-75)$ & 9 \\
Engida et al. (2012) [41] & 202 & 96.5 & Addis Ababa & $57(50-64)$ & 8 \\
Sena et al. (2012) [42] & 340 & 80.6 & Oromia & $6.9(4-10)$ & 9 \\
Gutema et al. (2015) & 309 & 89 & SNNP & $54(48-59)$ & 9 \\
Daniel et al. (2016) [43] & 127 & 100 & SNNP & $26(18-34)$ & 9 \\
Haftom et al. (2015) [44] & 233 & 93 & Tigray & $57(51-64)$ & 9 \\
Guesh et al. (2018) [45] & 414 & 98.1 & Tigray & $83(31-43)$ \\
Haile et al. (2019) [46] & 436 & 95 & SNNP & $55.4(2-9)$ \\
Tesfay et al. (2019) [36] & 220 & 98 & Tigray & $73.3(21-32)$ & 9 \\
Azeb et al. (2017) [47] & 605 & 98.1 & Addis Ababa & $69(36-45)$ & 9 \\
\hline
\end{tabular}

Study

ID

Fantu A.et al(2012)

Habtamu R.et al(2017)

Wakeshe W.et al(2015)

Negash W.et al(2013)

Haymanot M: et al(2015)

Tesfay H. et al(2017)

Desalegne A. et al(2015)

Kidist E. et al(2016)

Kidest G.et al(2016)

D.Markos et al(2014)

Engida Y.et al(2012)

Sena B.et al(2012)

Gutema C. et al(2015)

Daniel B.et al(2016)

Haftom G. et al (2015)

Yosef Haile.et al(2019)

Tesfay H. et al(2019)

Azeb A.et al(2017)

Guesh W.et al(2017)

Overall (I-squared $=99.4 \%, p=0.000$ )

NOTE: Weights are from random effects analysis
Prevalence $(95 \% \mathrm{Cl})$

$29.00(24.44,33.56)$

- $89.10(85.02,93.18)$

- $84.60(80.26,88.94)$

$40.20(35.41,44.99)$

- $92.60(90.16,95.04)$

$73.30(67.45,79.15)$

$53.80(47.89,59.71)$

$51.00(45.34,56.66)$

$72.60(68.44,76.76)$

$70.20(65.72,74.68)$

$57.30(50.48,64.12)$

$6.90(4.21,9.59)$

$53.90(48.34,59.46)$

$26.00(18.37,33.63)$

$57.40(51.05,63.75)$

$55.40(50.73,60.07)$

$73.30(67.45,79.15)$

$69.00(65.31,72.69)$

$+83.00(79.38,86.62)$

$59.95(46.81,73.09)$

Fig. 2 Forest plot for the prevalence of partograph use among obstetric care providers in Ethiopia, 2020 
estimated prevalence of partograph use among obstetric care providers in Ethiopia was 59.95\% (95\% CI 46.873.09, $\left.I^{2}=99.4 \%, P<0.001\right)$.

\section{Publication bias}

The funnel plot was assessed for asymmetry distribution of prevalence of partograph use among obstetric care providers by visual inspection (Fig. 3). Egger's regression test showed a $P$ value of 0.759 with no evidence of publication bias.

\section{Sensitivity analysis}

This systematic review and meta-analysis showed that the point estimate of its omitted analysis lies within the confidence interval of the combined analysis. Therefore, trim-and-fill analysis was not further computed (Fig. 4).

\section{Subgroup analysis}

Subgroup analysis was employed with the evidence of heterogeneity. In this study, the Cochrane $I^{2}$ statistic was 99.4\%, $P<0.001$, which showed the evidence of marked heterogeneity. Therefore, subgroup analysis was done using the study region and year of study. As a result, the use of partograph was highest in Addis Ababa 73.4\%, whereas $70.95 \%$ in the study conducted between 2018 and 2019 (Figs. 5 and 6).

\section{Determinants of partograph utilization in Ethiopia}

The association between midwifery profession, presence of supervision, Basic Emergency Obstetric and Newborn Care (BEmONC) training, attitude, knowledge of partograph, on-the-job refresher training on partograph, favorable attitude towards partograph, and working at health centers with partograph use was carried out.

In this meta-analysis, to identify the associated factors, eight articles were used for midwifery profession [31-35, $40,43,48]$, five for knowledge of partograph [33, 34, 37, $46,47]$, three for attitude $[34,35,46]$, five for on-the-job refresher training on partograph [31, 35, 40, 46, 47], seven for BEmONC training [31, 33-37, 44], four for presence of supervision $[31,32,40,43]$, and six for working at health center [35, 37, 38, 41, 46, 48].

Obstetric care providers who were midwives were 3.97 times more likely to use partograph as a decision-making tool. Those obstetric care providers who received BEmONC training were 2.9 times more likely to use partograph. The odds ratio of on-the-job refresher training on partograph to use partograph was 5.7. Obstetric care providers who supervised were 3.21 times more likely to use partograph. Additionally, obstetric care providers who had a good knowledge of partograph were 2.5 times more likely to use partograph.

Obstetric care providers who had a favorable attitude towards partograph utilization were 2.12 more likely to utilize partograph as a decision-making tool. Moreover, those obstetric care providers working at the health center were 3.5 times more likely to use partograph (Table 2).

\section{Discussion}

The use of partograph in this review ranged from 6.9 to $92 \%$. The highest use of partograph use was from Addis

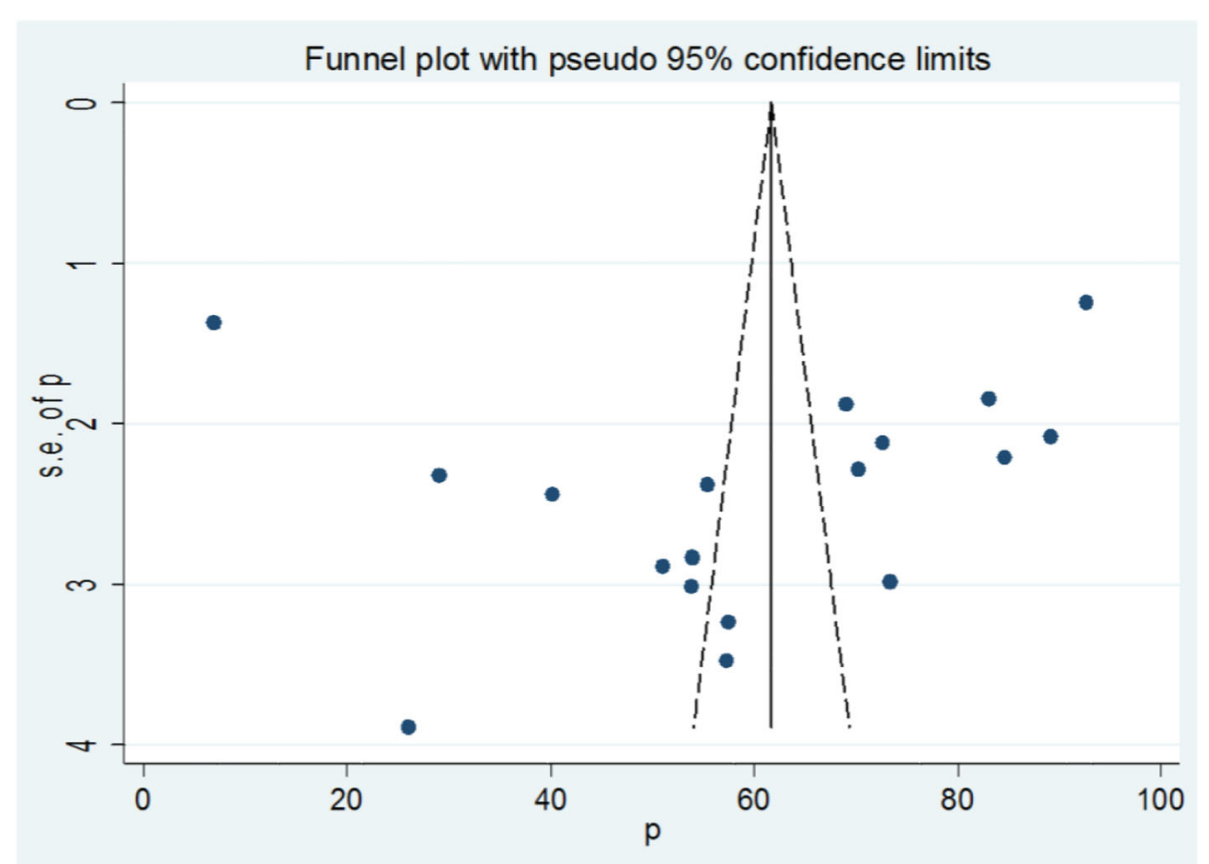

Fig. 3 Funnel plot with 95\% confidence limits of the pooled prevalence of partograph use among obstetric care providers in Ethiopia, 2020 
Meta-analysis estimates, given named study is omitted

I Lower Cl Limit I Upper Cl Limit

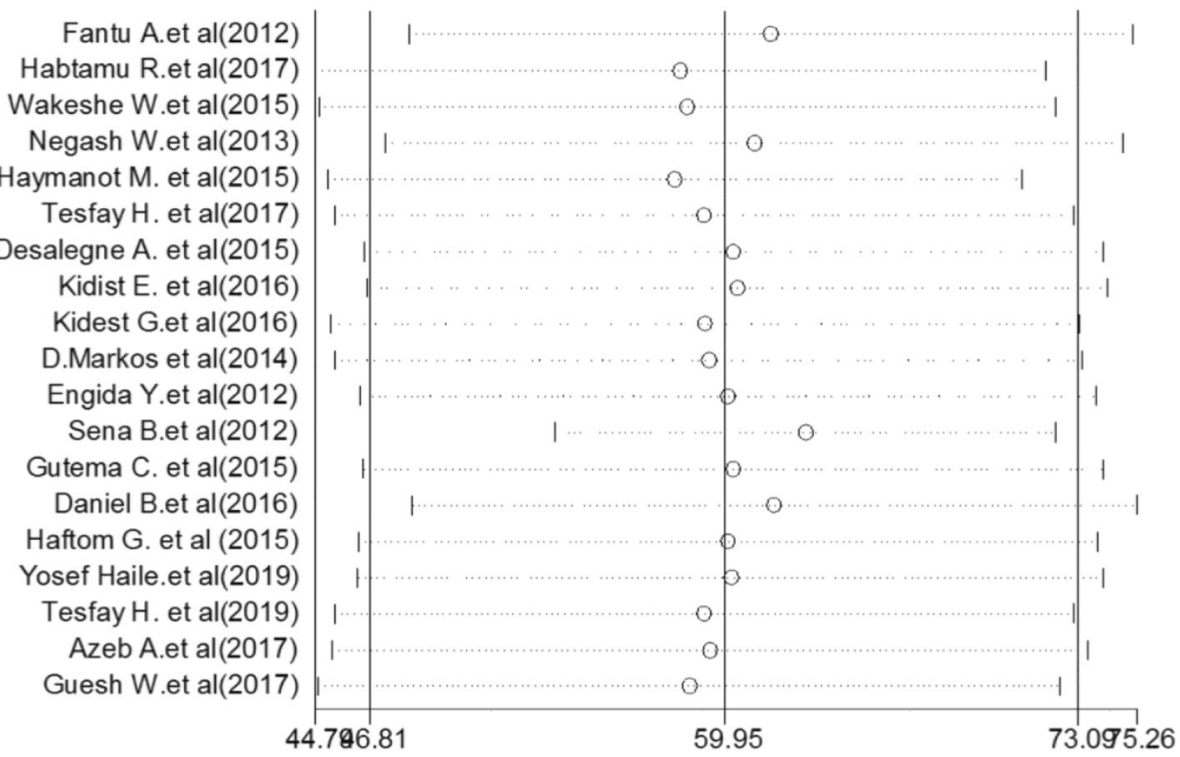

Fig. 4 Sensitivity analysis of the pooled prevalence of partograph use among obstetric care providers in Ethiopia

Author

Amhara

Fantu A.et al(2012)

Negash W.et al(2013)

Desalegne A. et al(2015)

Subtotal (I-squared $=95.3 \%, p=0.000)$

Oromia

Habtamu R.et al(2017)

Wakeshe W.et al(2015)

Sena B.et al(2012)

Subtotal (1-squared $=99.9 \%, p=0.000)$

Addis Ababa

Haymanot M. et al(2015

Engida Y.et al(2012)

Azeb A.et al(2017)

Subtotal (1-squared $=98.8 \%, p=0.000)$

Tigray

Tesfay H. et al(2017)

Haftom G. et al (2015)

Tesfay H. et al(2019)

Guesh W.et al(2017)

Subtotal (I-squared $=93.9 \%, p=0.000)$

SNN

Kidist E. et al(2016)

Kidest G.et al(2016)

D.Markos et al(2014)

Gutema C. et al(2015)

Daniel B.et al(2016)

Yosef Haile.et al(2019)

Subtotal (I-squared $=96.7 \%, p=0.000)$

Overall (1-squared $=99.4 \%, p=0.000$ )

NOTE: Weights are from random effects analysis
Prevalence $(95 \% \mathrm{Cl})$

$29.00(24.44,33.56)$

$40.20(35.41,44.99)$

$53.80(47.89,59.71)$

40.89 (27.40, 54.38)

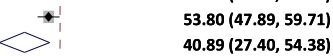

\begin{tabular}{l}
$-\quad 89.10(85.02,93.18)$ \\
\hline
\end{tabular}

$89.10(85.02,93.18)$ $6.90(4.21,9.59)$

$60.18(1.75,118.61)$

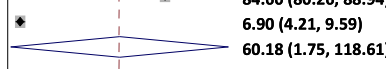

- $92.60(90.16,95.04)$

$\begin{array}{r}\quad 57.30(50.48,64.12) \\ -\quad 59.00(65.31,72.69) \\ \hline\end{array}$

$\quad 69.00(65.31,72.69)$

$73.14(52.52,93.76)$

$73.30(67.45,79.15)$

$57.40(51.05,63.75)$

$73.30(67.45,79.15)$

$83.00(79.38,86.62)$

$71.93(61.30,82.56)$

51.00 (45.34, 56.66)

$72.60(68.44,76.76)$

$70.20(65.72,74.68)$

$53.90(48.34,59.46)$

$26.00(18.37,33.63)$

$\diamond \quad \begin{aligned} & 55.40(50.73,60.07) \\ & 55.10(43.64,66.56)\end{aligned}$

$\overbrace{}^{5} \quad \begin{aligned} & 55.40(50.73,60.07) \\ & 55.10(43.64,66.56)\end{aligned}$

$\uparrow \quad 59.95(46.81,73.09)$

a10

Fig. 5 Subgroup analysis of the pooled prevalence of partograph use among obstetric care providers based on the study region 


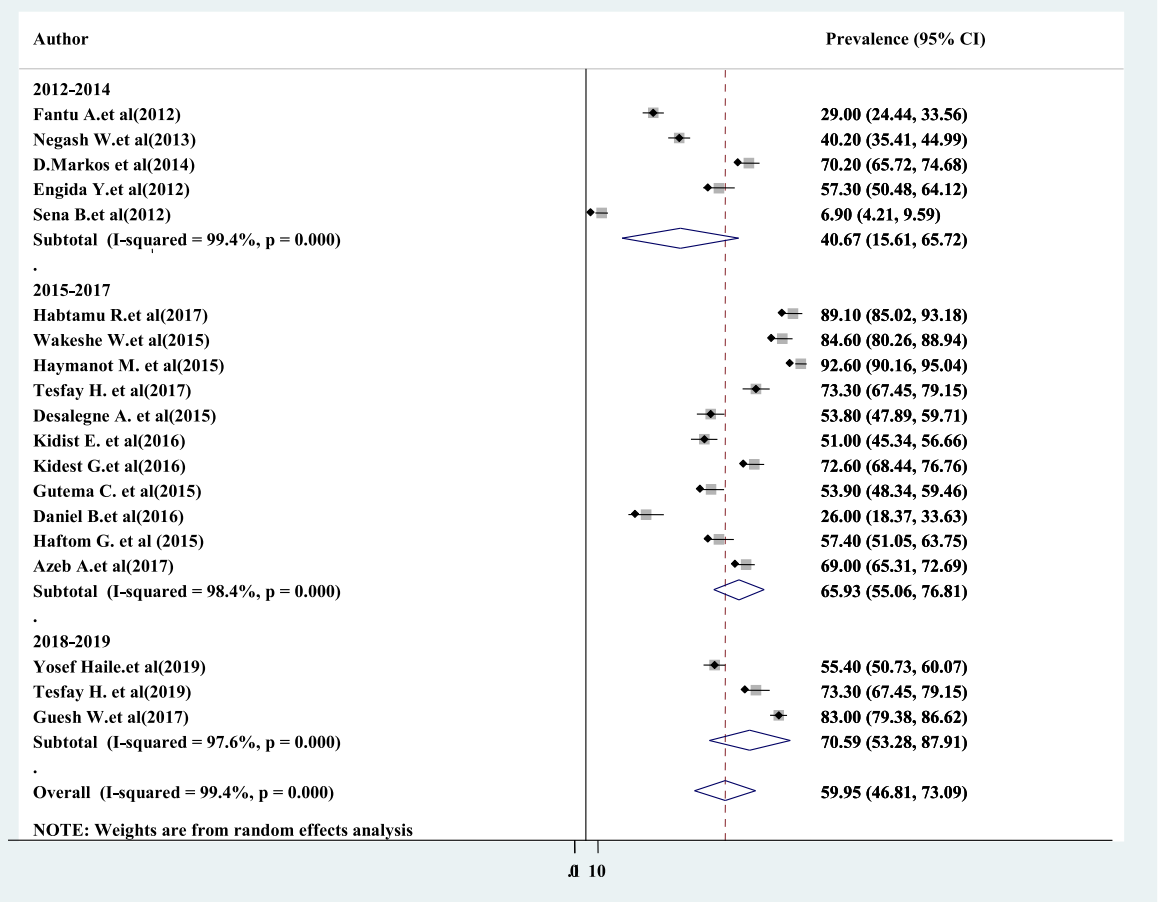

Fig. 6 Subgroup analysis of the pooled prevalence of partograph use among obstetric care providers based on the year of study

Ababa [35] while the lowest one was from Oromia region [42]. The purpose of this review was to assess the pooled prevalence and associated factors of partograph use by reviewing the finding of available studies. The pooled prevalence of partograph use in Ethiopia was $59.9 \%$.

The use of partograph for all laboring mothers is recommended by the WHO as a means to monitor and record maternal and fetal well-being, as it can identify maternal or fetal distress and abnormalities in the progress of labor that require further action, including referral. This can reduce complications from prolonged labor for the mother (obstetric fistula, postpartum hemorrhage, sepsis, uterine rupture, and its sequelae) and for the infant (death, anoxia, and infections) [4951]. Thus, the use of partograph in this study was low.
The findings of the current study is lower than studies in South Africa [52] which accounted for 79.4\%, Ghana [53] 87\%, Gambia [54] 78\%, and Uganda [55] 69.9\%. The differences between these findings might be due to difference in level of knowledge of obstetric care providers and different strategies in partograph implementation; as in Ghana, obstetric care providers received specific training in the use of partograph [56], 83.8\% trained in South Africa [52], and the application of improving partograph use in Uganda through training, coaching, and mentoring [57]. Moreover, in the studies of Gambia, Uganda, and South Africa, the participants were only midwives and doctors by profession, whereas this study included all obstetric care providers including nurses, health extension workers, public health officers, and IESOs.

Table 2 Descriptive summary of determinant factors for partograph utilization among obstetric care providers

\begin{tabular}{llll}
\hline Variable name & No. of included studies & OR (95\% Cl) & Overall $(\mathbf{I}$-squared, $\boldsymbol{P}$ value $)$ \\
\hline Midwifery profession & 8 & $3.97(2.63-5.99)$ & $28.8 \%, P=0.198$ \\
Presence of supervision & 4 & $3.21(2.22-4.66)$ & $0.0 \%, P=0.742$ \\
Emergency Obstetric and Newborn Care training & 7 & $2.90(2.19-3.84)$ & $36.9 \%, P=0.134$ \\
Knowledge of partograph & 5 & $2.46(1.60-3.77)$ & $64.5 \%, P=0.024$ \\
Attitude towards partograph & 3 & $2.12(1.48-3.04)$ & $0.0 \%, P=0.573$ \\
On-the-job refresher training on partograph & 5 & $5.66(2.48-12.92)$ & $87.8 \%, P=0.000$ \\
Working at health center & 6 & $3.50(2.49-4.92)$ & $49.1 \%, P=0.08$ \\
\hline
\end{tabular}


The prevalence of partograph use in this study is higher than the study done in Rwanda [58] 41.22\%, Cameroon [59] 32.4\%, and Nigeria [50] 37.5\%. The possible reason might be the Federal Ministry of Health has set targets and working for facility delivery coverage at $90 \%$ and to enable all health centers to use partograph, and to provide all BEmONC functions [60].

The finding of this meta-analysis revealed that midwives were 3.97 times more likely to use partograph compared to other obstetric care providers. This result agrees with studies conducted in Nigeria [50] and South Africa [61]. This might be justified by midwives to have more chances of being assigned in labor wards and consequently received training on partograph, which might in turn have improved their knowledge, skill, and attitude to use partograph than others.

In this study, obstetric care providers who supervised were 3.21 times more likely to utilize partograph than their counterparts. The possible reason could be due to the availability of well-designed and coordinated programs like the strength of mentorship, and supportive supervision of obstetric care providers may affect the use of partograph. Thus, effective utilization of obstetric care provider's knowledge advancement through refresher training, including practical demonstration, supportive supervision, and on-site partograph audits by trained supervisors, should also be prioritized [55, 62, 63].

Obstetric care providers who received Basic Emergency Obstetric and Newborn care training were 2.9 times more likely to use partograph than who did not receive. This finding is in line with a study done in Malawi [64] and Nigeria [65]. The reason might be receiving Emergency Obstetric and Newborn care training to capacitate obstetric care providers to interpret the components of partograph, to follow best practices during childbirth, and to use partograph as a decisionmaking tool.

Obstetric care providers who had adequate knowledge on partograph were 2.5 times more likely to utilize partograph than their counterparts. This result was supported by other studies $[65,66]$. The possible reason might be the knowledge that enables them to understand what critical progress of labor will occur and decide on alternatives such as referral and caesarian section which encourage obstetric care providers to use partograph as a decision-making tool.

Additionally, obstetric care providers who received onthe-job refresher training on partograph were 5.7 times more likely to use partograph compared to those who did not receive. This result in supported by a study in Tanzania [67]. The possible reason might be health care providers who received on-the-job refresher training on partograph had better knowledge, skills, and confidence about partograph use, which in turn improves its use.
Partograph utilization was 2.12 times higher among obstetric care providers who had a favorable attitude as compared to those who had an unfavorable attitude. This is in agreement with the studies done in Nigeria [50]. The possible reason might be having a favorable attitude towards partograph might come after having knowledge about partograph that may influence partograph use.

According to this study, obstetric care providers who have been working at health centers were 3.5 times more likely to use partograph compared to those who have been working at hospitals. The possible explanation might be the majority of the obstetric care providers working in health centers received on-the-job refresher training on partograph, BEONC training, and frequent supervision as compared to those working in hospitals [68]. The other reason might be health center obstetric care providers use partograph as a guide to take early action, to have adequate evidence, and to refer to higher health institution, which might increase its use.

\section{Limitation}

Since it is the first systematic review and meta-analysis, it is taken as strength. The included articles were restricted to the English language only; this is a limitation of the study as it missed studies published in local languages. This review has not been registered online.

\section{Conclusion}

The overall pooled prevalence of partograph utilization among obstetric care providers in Ethiopia was low. Therefore, supportive supervision, providing Basic Emergency Obstetric and Newborn Care training, on-the-job refresher training on partograph, and promoting midwifery profession are strongly recommended to increase the use of partograph.

\section{Supplementary Information}

Supplementary information accompanies this paper at https://doi.org/10. 1186/s13643-020-01505-4.

Additional file 1. PRISMA checklist.

Additional file 2. NOS quality score.

\section{Abbreviations}

AA: Addis Ababa; Cl: Confidence interval; EmOC: Emergency obstetric care NC: Newborn care; OR: Odds ratio; PRISMA: Preferred Reporting Items for Systematic Reviews and Meta-Analyses; SNNP: Southern Nation Nationality and People; WHO: World Health Organization

\section{Acknowledgements}

N/A

Authors' contributions

Both authors (AAA) and (BFZ) contributed to all the process from conception of the research protocol to the reading and approval of the final manuscript. Correspondence goes to AAA. 


\section{Funding}

No funding was obtained for this study.

\section{Availability of data and materials}

The data sets generated during the current study are available from the corresponding author on reasonable request.

\section{Ethics approval and consent to participate} Not applicable.

\section{Consent for publication}

Not applicable.

\section{Competing interests}

All authors declare that they have no competing interests.

\section{Author details}

${ }^{1}$ Department of Midwifery, College of Medicine and Health Sciences, Bahir Dar University, Bahir Dar, Ethiopia. ${ }^{2}$ Department of Orthopedics, College of Medicine and Health Sciences, Bahir Dar University, Bahir Dar, Ethiopia.

Received: 22 May 2020 Accepted: 13 October 2020

Published online: 03 November 2020

\section{References}

1. WHO. Trends in maternal mortality: 1990 to 2015: estimates by WHO, U., UNFPA, World Bank Group and the United Nations population division. Geneva, Switzerland: World Health Organization; 2015.

2. BL., S. Effect of partogram use on outcomes for women in spontaneous labour at term: RHL Commentary. The WHO Reproductive Health Library. Geneva: World Health Organization; 2009.

3. ICF., C.S.A.C.E.a. Ethiopia demographic and health survey 2016. Addis Ababa, Ethiopia, and Rockville, Marryland, USA: CSA and ICF; 2016.

4. Organization, W.H. Reduction of maternal mortality: a joint WHO/UNFPA/ UNICEF/World Bank statement. Geneva: World Health Organization; 1999.

5. Ali A, Masakhwe BA. WHO midwifery education module 3 managing prolonged and obstructed labour. Training Course in Sexual and Reproductive Health Research; 2010.

6. Organization, W.H. Making pregnancy safer: the critical role of the skilled attendant: a joint statement by WHO, ICM and FIGO, in Making pregnancy safer: the critical role of the skilled attendant: a joint statement by $\mathrm{WHO}$, ICM and FIGO. Geneva: WHO; 2014.

7. Harrison MS, et al. Maternal mortality from obstructed labor: a MANDATE analysis of the ability of technology to save lives in sub-Saharan Africa. Am J Perinatol. 2016;33(9):873-81.

8. Mathai M. The partograph for the prevention of obstructed labor. Clin Obstet Gynecol. 2009;52(2):256-69.

9. Asibong U, O.I, Agan TU, Oku A, Opiah M, Essien EJ, et al. The use of the partograph in labor monitoring: a cross-sectional study among obstetric caregivers in general hospital, Calabar, Cross River state, Nigeria. Int J Women's Health. 2014;6:873.

10. Kayiga $\mathrm{H}$, et al. Improving the quality of obstetric care for women with obstructed labour in the national referral hospital in Uganda: lessons learnt from criteria based audit. BMC Pregnancy Childbirth. 2016;16(1):152.

11. Kabakyenga JK, et al. Individual and health facility factors and the risk for obstructed labour and its adverse outcomes in south-western Uganda. BMC Pregnancy Childbirth. 2011:11:73.

12. Black RE, Laxminarayan R, Temmerman M, Walker N, editors. Reproductive, Maternal, Newborn, and Child Health: Disease Control Priorities, Third Edition (Volume 2). Washington (DC): The International Bank for Reconstruction and Development / The World Bank; 2016. PMID:27227205.

13. EA., F. Primigravid labour. A graphic statistical analysis. Obstet Gynecol. 1995; 6:567-89.

14. World Health Organization partograph in management of labour. World Health Organization Maternal Health and Safe Motherhood Programme. Lancet. 1994;343(8910):1399-404.

15. Levin K, Kabagema J. Use of the partograph: effectiveness, training, modifications, and barriers - a literature review. Washington: United States Agency for International Development, Fistula Care, EngenderHealth; 2011. p. 28.
16. Organization, W.H, et al. Pregnancy, childbirth, postpartum, and newborn care: a guide for essential practice. New York: World Health Organization; 2003.

17. Organization, W.H. Managing complications in pregnancy and childbirth: a guide for midwives and doctors. Geneva: World Health Organization; 2017.

18. World Health Organization, United Nations Population Fund \& United Nations Children's Fund ( UNICEF). Managing complications inpregnancy and childbirth: a guide for midwives and doctors, 2nd ed. World Health Organization. 2017. https://apps.who.int/iris/handle/10665/255760.

19. Philpot RH. C.W.C.i.t.m.o.l.i.p., action line \& treatment of abnormal labor. J Obstet Gynecol Br Commonwealth. 1972;79:599-602.

20. Mukasa PK, et al. Uterine rupture in a teaching hospital in Mbarara, western Uganda, unmatched case- control study. Reprod Health. 2013;10:29.

21. Lavender T, Hart A, Smyth RM. Effect of partogram use on outcomes for women in spontaneous labour at term. Cochrane Database Syst Rev. 2013; (7):CD005461. https://doi.org/10.1002/14651858.CD005461.pub4.

22. Moher $D$, et al. Preferred reporting items for systematic reviews and metaanalyses: The PRISMA Statement. Public Library Sci Med. 2009;6(6):el000097.

23. Moher D, et al. Preferred reporting items for systematic reviews and metaanalyses: the PRISMA statement. PLoS Med. 2009;6(7):e1000097.

24. Downes MJ, et al. Development of a critical appraisal tool to assess the quality of cross-sectional studies (AXIS). BMJ open. 2016;6(12):e011458.

25. Viera AJ, Garrett JM. Understanding interobserver agreement: the kappa statistic. Fam med. 2005;37(5):360-3.

26. Sendeku FW, Azeze GG, Fenta SL. Perinatal asphyxia and its associated factors in Ethiopia: a systematic review and meta-analysis. BMC pediatrics. 2020;20(1):1-11.

27. DerSimonian R, Laird N. Meta-analysis in clinical trials. Control Clin Trials. 1986:7(3):177-88.

28. Huedo-Medina TB, et al. Assessing heterogeneity in meta-analysis: Q statistic or 12 index? Psychol Methods. 2006;11(2):193-206.

29. Higgins JP, A. D. Assessing risk of bias in included studies. Cochrane handbook for systematic reviews of interventions: Cochrane book series; 2008. p. 187-241.

30. Egger M, D.-S.G, Altman D. Systematic reviews in health care: meta-analysis in context. Chichester: Wiley; 2008

31. Abebe $F$, et al. Assessment of knowledge and utilization of the partograph among health professionals in Amhara region, Ethiopia. Sci J Clin Med. 2013;2(2):1-17.

32. Regasa $\mathrm{H}$, Tilahun $\mathrm{T}$, Adem H. Utilization of partograph and associated factors among obstetric care givers in hospitals of Western Oromia, Ethiopia. 2017. Panacea J Med Sci. 2018:8:21-4.

33. Wakeshe, W., Magnitude of partograph use and factors that affecting its utilization among obstetric caregivers in public health institutions of West Showa Zone, Oromia Regional state, Ethiopia. 2015 (2015-05-13 00:00:00).

34. Wakgari N, et al. Partograph utilization and associated factors among obstetric care providers in North Shoa Zone, Central Ethiopia: a cross sectional study. African health sciences. 2015;15(2):552-9.

35. Mezmur H, Semahegn A, Tegegne BS. Health professional's knowledge and use of the partograph in public health institutions in eastern Ethiopia: a cross-sectional study. BMC Pregnancy Childbirth. 2017;17(1):291.

36. Hailu T, et al. Assessment of partograph utilization and associated factors among obstetric care givers at public health institutions in central zone, Tigray, Ethiopia. BMC Res Notes. 2018;11(1):710.

37. Zelellw DA, Tegegne TK, Getie GA. Knowledge and attitude of obstetric care providers on partograph and its associated factors in East Gojjam Zone, Northwest Ethiopia. Adv Med. 2016;2016:6913165.

38. Kidist Eshetu EH. Dubale Dulla, Magnitude of partograph use and associated factors among obstetric care givers in public health institution in Sidama Zone, Southern Ethiopia. Diversity Equality Health Care. 2017;14(16):316-23.

39. Getu K, Eyasu T. Knowledge of partograph utilization and its associated factors: a cross-sectional survey in Wolaita Zone Southern Ethiopia. Int J Nurs Midwifery. 2019;11:1-6.

40. Markos D, Bogale D. Documentation status of the modified World Health Organization partograph in public health institutions of Bale zone, Ethiopia. Reprod Health. 2015;12(1):81.

41. Yisma E, et al. Completion of the modified World Health Organization (WHO) partograph during labour in public health institutions of Addis Ababa, Ethiopia. Reproductive health. 2013;10(1):23. 
42. Kitila SB, Gmariam A, Molla A, Nemera G. Utilization of Partograph during Labour and Birth Outcomes at Jimma University. J Preg Child Health. 2014;1: 101. https://doi.org/10.4172/2376-127X.1000101.

43. Daniel Bekele KB. Leta Hinkosa et al. Partograph utilization and associated factors among graduating health professional students in Asella Referal and Teaching Hospital, Ethiopia, 2016. Res Rev. 2017;6(2):12-18p.

44. Haftom Gebrehiwot SM. Tsige Araya, et al. Partograph: an essential tool for midwives to manage labor at public health institutions in Tigray, Northern Ethiopia. Res Rev. 2015;5(3):23-29p.

45. Gebreslassie GW, Weldegeorges DA, Assefa NE, Gebrehiwot BG, Gebremeskel SG, Tafere BB, Gebreheat G, Gebru TT, Kiros D, Tekola KB, Welesamuel TG. Utilization of the partograph and its associated factors among obstetric care providers in the Eastern zone of Tigray, Northern Ethiopia, 2017: a cross-sectional study. Pan Afr Med J. 2019:34:181 https:// doi.org/10.11604/pamj.2019.34.181.18246.

46. Haile, Y., et al., Partograph utilization and associated factors among obstetric care providers at public health facilities in Hadiya Zone, Southern Ethiopia. 2020.

47. Hagos AA, Teka EC, Degu G. Utilization of partograph and its associated factors among midwives working in public health institutions, Addis Ababa City Administration,Ethiopia. BMC Pregnancy Childbirth. 2017;20:49.

48. Gebreslassie GW, D.A.W, Assefa NE, Gebrehiwot BG, Gebremeskel SG, Tafere BB, Gebreheat G, Gebru TT, Kiros D, Tekola KB, Welesamuel TG. Utilization of the partograph and its associated factors among obstetric care providers in the Eastern zone of Tigray, Northern Ethiopia. Pan Afr Med J. 2019;34:181.

49. Liljestrand J. Strategies to reduce maternal mortality worldwide. Current opinion in Obstetrics and Gynecology. 2000;12(6):513-7.

50. Opiah MM, et al. Knowledge and utilization of the partograph among midwives in the Niger Delta Region of Nigeria. Afr J Reprod Health. 2012; 16(1):125-32.

51. Shinde KK, Bangal VB, Singh RK. Study of course of labour by modified WHO partograph. IJBAR. 2012;3(5):291-6.

52. Maphasha OM, et al. Use of the partogram by doctors and midwives at Odi District Hospital, Gauteng, South Africa. South Afr Family Pract. 2017;59(2): 82-6.

53. Anokye $\mathrm{R}$, et al. Use and completion of partograph during labour is associated with a reduced incidence of birth asphyxia: a retrospective study at a peri-urban setting in Ghana. J Health Popul Nutr. 2019;38(1):12.

54. Burama Badjie C-HK, Gua M-I, Lin K-C. Partograph use among midwives in the Gambia; 2013.

55. Ogwang S, Karyabakabo Z, Rutebemberwa E. Assessment of partogram use during labour in rujumbura health Sub district, Rukungiri district, Uganda. African Health Sciences. 2009;9(2):S27.

56. Floyd L. Helping midwives in Ghana to reduce maternal mortality. African Journal of Midwifery and Women's Health. 2013;7(1):34-8.

57. Fistula Care. Improving partograph use in Uganda through coaching and mentoring. New York: Fistula Care/EngenderHealth; 2013.

58. Bazirete $\mathrm{O}, \mathrm{Mbombo} \mathrm{N}$, Adejumo $\mathrm{O}$. Utilisation of the partogram among nurses and midwives in selected health facilities in the Eastern Province of Rwanda. Curationis. 2017;40(1):e1-9.

59. Sama CB, et al. Knowledge and utilization of the partograph: a crosssectional survey among obstetric care providers in urban referral public health institutions in northwest and southwest Cameroon. PLoS One. 2017; 12(2):e0172860.

60. ETHIOPIA. HSTP: Health Sector Transformation Plan: 2015/16 - 2019/20 (2008-2012 EFY). 2015.

61. Mathibe-Neke J, Lebeko F, Motupa B. The partograph: a labour management tool or a midwifery record? Int J Nurs Midwifery. 2013;5(8): 145-53.

62. Nwaneri A, et al. Evaluation of factors affecting the utilization of partograph by nurses/midwives in primary/secondary health facilities in Enugu Metropolis. Gynecol Obstet (Sunnyvale). 2017;7(8):3.

63. Khan ANS, et al. A cross-sectional study of partograph utilization as a decision making tool for referral of abnormal labour in primary health care facilities of Bangladesh. PloS one. 2018;13(9):e0203617.

64. Mandiwa C, Zamawe C. Documentation of the partograph in assessing the progress of labour by health care providers in Malawi's South-West zone. Reprod Health. 2017;14:134. https://doi.org/10.1186/s12978-017-0401-7.

65. Fawole AO, K.I.H, Adekanle DA. Knowledge and utilization of the partograph among obstetric care givers in south west Nigeria. Afr J Reprod Health. 2008;12(1):22-9.
66. OLORUNMOWAJU OM. THE EFFECTS OF MODIFIED WHO PARTOGRAPH ON MATERNAL AND PERINATAL OUTCOMES OF LABOUR IN GAMBO SAWABA GENERAL HOSPITAL, ZARIA. Faculty of Family Medicine, 2019.

67. Nyiawung FN, Amin ET, Fondungallah JA, Egbe TO. The Partogram: Knowledge, Attitude and Use by Healthcare Providers at Two Hospitals in the South West Region of Cameroon. Arch Community Med Public Health. 2018;4(2):073-077. https://doi.org/10.17352/2455-5479.000041.

68. Tiruneh GT, et al. The effect of implementation strength of basic emergency obstetric and newborn care (BEmONC) on facility deliveries and the met need for BEmONC at the primary health care level in Ethiopia. BMC Pregnancy and Childbirth. 2018;18(1):123.

\section{Publisher's Note}

Springer Nature remains neutral with regard to jurisdictional claims in published maps and institutional affiliations.
Ready to submit your research? Choose BMC and benefit from:

- fast, convenient online submission

- thorough peer review by experienced researchers in your field

- rapid publication on acceptance

- support for research data, including large and complex data types

- gold Open Access which fosters wider collaboration and increased citations

- maximum visibility for your research: over $100 \mathrm{M}$ website views per year

At BMC, research is always in progress.

Learn more biomedcentral.com/submissions 